\title{
"Um dois, feijão com arroz...": rimas e ludicidade como pretexto para estimular o gosto pela e a aprendizagem da leitura
}

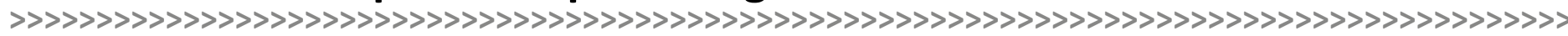

\author{
Idonézia Collodel Benetti* \\ João Paulo Roberti Junior** \\ Fernanda Ax Wilhelm***
}

\begin{abstract}
Resumo:
As rimas são conhecidas e usadas em muitas culturas em todo o mundo. O presente trabalho, relato de uma experiência com rimas, ancorado no poema lúdico de Tatiana Belinky “A alegre vovó Guida” pretende, além de abordar o assunto, contribuir com alguns exemplos de exercícios que podem ser utilizados em sala de aula, favorecendo o ensino/ aprendizagem da leitura e minimizando as dificuldades relacionadas a essa habilidade linguística. Os procedimentos utilizados foram aplicados com crianças do segundo ano de uma escola pública de uma cidade em Santa Catarina, no dia 26 de julho, dia da vovó e são assim descritos: a) aquecimento, b) leitura do poema pela professora, c) desenvolvimento com atividades lúdicas e d) reescrita do poema de forma a ficar coerente com uma vovó diferente. Os momentos aproveitados, e utilizados nessas atividades, foram interessantes e envolventes para as crianças e para a professora.
\end{abstract}

\section{Palavras-chave:}

Rimas. Ludicidade. Consciência fonológica. Leitura.

\begin{abstract}
:
Rhymes are known and used in many cultures around the world. The present work, a report of an experience with rhymes, anchored in the playful poem from Tatiana Belinky "Joyful Grandma Marge" intends, besides addressing the subject, contribute some examples of exercises that can be used in the classroom, encouraging the teaching/learning of reading and minimizing the difficulties related to that language skill. The procedures were applied to children in the second year of a public school in a city in Santa Catarina, on 26 July - the Grandma's day - and are described as follows: a) warming up, b) reading the poem by the teacher, $c$ ) exercising with the development of fun activities and d) rewriting the poem in order to stay consistent with a different grandma. Moments took and used in these activities were interesting and engaging for the children and the teacher.
\end{abstract}

\section{Keywords:}

Rhymes. Playfulness. Phonological awareness. Reading.

\section{Introdução}

O aprendizado da leitura é uma meta educacional e social importante a ser alcançada. Para crianças e adultos, a habilidade de ler descortina novos horizontes e oportunidades, promovendo o ganho de novos conhecimentos. No mundo letrado, pode-se apreciar a

\footnotetext{
* > Mestre em Língua Inglesa e Psicologia e Doutoranda em Saúde Coletiva na Universidade Federal de Santa Catarina. E-mail: idonezia@hotmail.com

** > Mestre em Antropologia Social pela Universidade Federal de Santa Catarina e professor do Departamento de Pedagogia da UNIDAVI.

E-mail: joaoroberti@gmail.com

*** > Professora Doutora do Departamento de Psicologia da Universidade Federal de Roraima.

E-mail: fernandaax@gmail.com
} 
literatura e realizar muitas tarefas do dia a dia que fazem parte da vida moderna, tais como: ler jornais, e-mails, lista de compras, letreiros de ônibus, manuais de instrução etc. Para muitas pessoas, a aprendizagem da leitura acontece com facilidade; entretanto, algumas precisam de recursos adicionais.

Este relato de experiência evidencia a importância do uso das rimas para despertar a consciência fonológica das palavras e para pavimentar o caminho da fluência na leitura. Também, a entonação de voz utilizada serviu para marcar a diferença entre o tom usado para fazer as leituras de histórias utilizadas em aulas anteriores, ilustrando como se deve proceder para ler diferentes gêneros literários.

\section{Revisão da literatura}

As rimas são conhecidas e usadas em muitas culturas em todo o mundo. No passado, elas foram utilizadas como um recurso para a liberdade de expressão - preservando a memória dos grupos sociais, acontecimentos históricos e políticos - através de documentação oral. As rimas também fazem parte de uma tradição, cujos participantes principais são crianças. É importante reforçar que as rimas continuam a ser ensinadas ao público infantil até hoje e, mesmo que elas pareçam datadas e algumas vezes não fazerem muito sentido para a geração atual, pesquisas mostram que rimar pode ser benéfico para o desenvolvimento de habilidades verbais e para a compreensão básica de uma criança, promovendo, entre tantos benefícios, o gosto pela e a aprendizagem da leitura.

Ainda precisamos aprender muito sobre as origens da consciência fonológica, mas uma teoria que transita entre os estudiosos do assunto é a de que as crianças aprendem a analisar os sons das palavras com o auxílio de rotinas linguísticas comuns. As rimas, particularmente as rimas infantis, são um exemplo, porque apresentam componentes que compartilham sons semelhantes. Então, reconhecer que duas palavras possuem rima é saber algo sobre seus sons e sobre os componentes que fazem parte delas.

Essa teoria foi investigada em um estudo de 15 meses, que começou quando as crianças tinham três anos e quatro meses. Avaliações foram feitas sobre o conhecimento de rimas e habilidades fonológicas, particularmente na detecção e produção de rimas e aliterações - repetição de fonemas no início, meio de palavras próximas, ou em frases ou versos em sequência. A classe social e o nível educacional dos pais também foram avaliados, e foi encontrada uma relação forte entre o conhecimento de rimas e o desenvolvimento de habilidades fonológicas, que permaneceu significativa quando as diferenças entre QI e o conhecimento social foram controlados. As rimas e a produção delas, juntamente com a aliteração, foram relacionadas à leitura precoce (SHEINGOLD; FOUNDAS, 1978).

Vale salientar que a consciência fonológica é o processo de percepção de que a língua falada pode ser segmentada em várias unidades distintas. Em outras palavras, uma frase pode ser segmentada em palavras, as palavras, em sílabas e as sílabas em fonemas, tendo a consciência de que essas mesmas unidades se repetem em diferentes palavras. Então, aproveitando que as rimas fazem parte das brincadeiras das crianças, esse trabalho pretende, além de abordar o assunto, contribuir com alguns exemplos de exercícios que podem ser utilizados em sala de aula, favorecendo o ensino/aprendizagem da leitura, minimizando as dificuldades relacionadas a essa habilidade linguística.

Pesquisas têm revelado que a habilidade de rimar, antes de iniciar o letramento, tem sido um excelente preditor para a leitura (GOSWAMI, 1990). Uma das razões para essa relação pode ser atribuída ao fato de que as crianças, que brincam com rimas antes de iniciar o processo de letramento, percebem com mais facilidade e rapidez que essas 
palavras também tendem a compartilhar os mesmos padrões de ortografia, ficando mais fácil usar essas semelhanças na grafia e para fazer previsões (analogias) sobre como as novas palavras escritas soarão.

Em crianças da Educação Infantil, estudos têm mostrado que as rimas facilitam a retenção de curto prazo, quando elas precisam recontar histórias. Nesse caso, a rima se mostrou uma excelente ferramenta para melhorar a lembrança das palavras e a sequência dos fatos apresentados, quando comparadas com as apresentações que não possuíam rimas (JOHNSON; HAYES, 1987).

Embora estudos tenham evidenciado que as crianças mais velhas e os adultos tendem a processar melhor as palavras, principalmente em função da semântica, ou significado (DEWHURST; ROBINSON, 2004), as rimas ainda têm um papel pivotal para a percepção auditiva da aprendizagem da língua e no ensino da linguagem escrita. A partir do título desse trabalho, pode-se perceber que a rima pode ter função educativa para as crianças, que vão além da leitura, implicando também o ensino de números inteiros e a construção das fundações da aprendizagem matemática, tornando-se uma forma mais fácil de lembrar a ordem dos números.

Assim, pode-se afirmar que os jogos de linguagem são uma parte normal e frequente na vida do adulto e no comportamento da criança. Pesquisas evidenciam que o foco em jogos de linguagem pode ajudar a preencher a lacuna entre o mundo da casa/parque infantil e o da sala de aula (VLOEDGRAVEN; VERHOEVEN, 2007). A exposição às rimas favorece não somente o progresso da leitura como também desenvolvimento de várias habilidades linguísticas, tais como: memória e consciência fonológica, aumento do vocabulário, progresso da linguagem oral, percepção de sequência lógica, compreensão da linguagem oral e escrita etc. Além disso, as rimas estimulam as crianças a praticarem o ritmo da língua. É prudente enfatizar que dominar uma língua não é apenas saber usar as palavras, mas também manipular vários elementos, tais como: a entonação, o volume, a inflexão, a modulação da voz, articulação e pronúncia clara das palavras etc., que são enfatizados nos contextos permeados pelas rimas (QING-FENG, 2007).

\section{Contexto e descrição da experiência}

Neste relato, o trabalho com rimas esteve ancorado no poema lúdico de Tatiana Belinky A alegre vovó Guida, com objetivos de encorajar mais envolvimento e segurança na leitura, mais consciência fonológica e mais prazer na realização das tarefas pedagógicas. Os procedimentos que seguem, foram aplicados com crianças do $2^{\circ}$ Ano do Ensino Fundamental de uma escola pública municipal, de uma cidade em Santa Catarina, no dia 26 de julho, Dia da Vovó. A referida escola situa-se na zona urbana e atende alunos do Ensino Fundamental I e II. Há duas turmas de 2o Ano nessa unidade escolar: uma no período matutino e outra no vespertino, atendidas pela mesma professora, pedagoga com Ensino Superior, que utilizou os mesmos procedimentos em suas turmas, nos diferentes períodos.

Ambas as turmas - uma com 20 alunos e outra com 18 - possuem crianças na faixa etária entre seis e sete anos, oriundas de famílias com renda total entre dois e quatro salários mínimos. Os momentos, utilizados nessas atividades, foram interessantes e prazerosos para as crianças e para a professora, que começou sua aula com uma atividade de sensibilização, envolvendo os seguintes procedimentos:

a) solicitou que as crianças dissessem o nome de suas avós e que as descrevessem;

b) anunciou que eles iriam conhecer a vovó do poema - uma avó diferente;

c) leu o poema para eles dramatizando. 
A sequência de procedimentos albergou os seguintes passos:

a. ler o poema novamente e pedir que as crianças dissessem algo maluco que a vovó Guida fez;

b. pedir que escutassem o poema novamente e se manifestassem, quando não soubessem o significado de alguma palavra;

c. distribuir estrofes do poema para decorar e pedir que cada um recitasse uma estrofe na ordem do poema;

d. ler o poema com lacunas e parar antes das mesmas, para que as crianças completassem (Ex.: Ontem, na cozinha escura, pôs no forno a (dentadura).

A professora levou os seguintes acessórios/objetos: peruca, dentadura, tigela, gamela, óculos, sapato, roupa, carro, carteira, bolsa, geladeira, óculos, colher, sopa, queijo, leite, cozinha, forno. Então, formou equipes nas quais um aluno lia uma parte do poema e o outro dramatizava, usando os acessórios/objetos.

Logo após, foi realizado o jogo das rimas, para consolidar o conhecimento já trabalhado. Com base nas rimas do poema, a professora formulou sentenças e leu as frases, para os alunos tentarem adivinhar as palavras. Cada palavra adivinhada deveria ser escrita com o alfabeto móvel, conforme exercício que segue.

\section{Atividade 1 - Ouça o professor e diga a palavra adequada à sentença. Depois, escreva cada palavra com o alfabeto móvel.}

a. É de ferro, o cavalo usa nas patas e rima com dentadura (Resposta: ferradura).

b. Gosta de queijo, não gosta de gato e rima com sapato (R: rato).

c. É da turma da Mônica, tem problemas na fala e rima com cozinha (R: Cebolinha).

d. É de cera. É usada para iluminar e rima com gamela (R: vela).

e. Pode ser de plástico, madeira, ou metal. Fica ao redor da mesa e rima com faceira (R: cadeira).

Outros exercícios para trabalhar leitura e escrita foram realizados, a saber:

a. Exercício de classificação: foram escritas palavras do poema em cartelas (peruca, dentadura, tigela, gamela, óculos, sapato, roupa, carro, carteira, bolsa, geladeira, óculos, colher, sopa, queijo, leite, cozinha, forno, boca, pé, nariz, cabeça etc.). As crianças deveriam manuseá-las e classificá-las de acordo com os seguintes critérios: acessórios de cozinha, objetos pessoais, itens de alimentação.

b. Jogo dos erros: foi retirada uma lista de palavras do poema e, em cada uma, foi acrescentada, omitida ou substituída uma letra, que não fazia parte da palavra. A criança deveria localizar as alterações.

c. Bingo de palavras: com palavras retiradas do poema, foram elaboradas cartelas para brincar com as crianças.

d. Reescrever o poema: o poema foi oferecido com lacunas de forma a ser reescrito para ficar coerente com uma vovó diferente. 


\section{A Alegre Vovó Ada}

A alegre vovó Ada

É um bocado

Vejam só o que esta vovó

Realizou num dia só.

Por que é muito e alegre a vovó Ada?

Ontem, na cozinha iluminada

Pôs no forno a

E na boca, ela

Um pouco de

Não é mesmo a alegre vovó Ada?

Para dar de beber ao gato,

Pôs o leite no

E no pé - coisa esperada!

Pôs sua alaranjada.

Não é mesmo a alegre vovó Ada?

Sua vida não é sopa -

Bem passada pôs a roupa,

Na cabeça - bem próprio dela!

Pôs, faceira, uma amarela...

Não é mesmo a alegre vovó Ada?

Pra descer até o subsolo

Pôs um a tiracolo,

E a bolsa com a carteira.

Ela guardou na

Não é mesmo a alegre vovó Ada?

E antes de sair de casa,

Acendeu um bom incenso,

E após cheirá-lo inteiro,

Limpou todo o

Não é mesmo a alegre vovó $A d a$ ?

Pra almoçar, toda feliz, pôs no nariz,

E na face, pôs - que mais?

Seus óculos bifocais!

Gente, como é a amável vovó $A d a !$ 
a. Brincando com as rimas: as crianças deveriam ler e completar as frases com rimas, usando as palavras do quadro.

* fim * tigela $^{*}$ sapato ${ }^{\star}$ peruca ${ }^{*}$ rima ${ }^{\star}$ saúde ${ }^{\star}$ forno * boné ${ }^{\star}$ remédio

Bambalalão pirulituca: no pé não se põe peruca.

Bambalalão pirulitude: fumar faz mal à

Bambalalão pirulitorno: você já viu dentadura no ___ ?

Bambalalão pirulipato: lugar de leite não é no

Bambalalão pirulitela: na cabeça se põe

Bambalalão pirulitédio: no nariz a gente coloca

Bambalalão pirulité: na cabeça se põe

Bambalalão pirulitima: é fácil fazer

Bambalalão pirulitim: rimamos até o

b. Complete o quadro, comparando as duas vovós.

\begin{tabular}{|l|l|l|}
\multicolumn{1}{|c|}{ Diferenças } & Semelhanças \\
\hline Vovó Guida & & Vovó Ada \\
\hline Distraída & & \\
\hline Usa peruca & & \\
\hline Usa roupa do avesso etc. ${ }^{1}$ & & \\
\hline
\end{tabular}

\section{Atividade 2 - Outros exercícios}

a. Figura surpresa: foram recortadas várias figuras de jornais e revistas e colocadas em uma pilha com a imagem virada para baixo. A criança pegava a primeira figura da pilha e dizia uma palavra que rimasse com a imagem da figura.

b. Treino de rimas: várias figuras de objetos que rimam com três ${ }^{2}$ terminações diferentes foram recortadas de revistas. Ex.: palavras terminadas em /ão/, /sa/, /ço/. Estas terminações foram escritas no quadro de modo que cada uma delas ficasse em uma coluna. Cada criança, então, retirava uma figura, dizia o nome da figura e colocava com fita adesiva na coluna correspondente ao som final da palavra.

$1>0$ exercício aqui está reduzido. Entretanto, podem ser explorados outros itens do poema.

$2>$ Podem ser usadas mais de três formas, dependendo do nível de cada turma.

\section{Avaliação dos resultados}

O impacto positivo do uso das rimas na aprendizagem da leitura é fato comprovado cientificamente. $\mathrm{O}$ desenvolvimento das crianças, como leitores e escritores, ocorre à medida que eles se envolvem em uma variedade de experiências de alfabetização. Porque as crianças pré-escolares chegam à escola com um conhecimento limitado de leitura e de escrita, e vivem em uma sociedade letrada, a alfabetização constitui-se uma parte fundamental do currículo. O desafio é entender como as crianças se desenvolvem como alunos de alfabetização, para fornecer um currículo que os envolva ativamente na alfabetização e onde o foco esteja na aprendizagem delas, em vez de em métodos centrados no professor. 
Nesta experiência, pudemos observar o prazer do trabalho com a ludicidade das rimas em um poema considerado engraçado. As crianças se divertiram, enquanto faziam as tarefas solicitadas. Ademais, elas demonstraram satisfação na repetição dos sons ao final das palavras e percebemos a ampliação do vocabulário - os alunos aprenderam palavras desconhecidas como "gamela" e "incenso".

Constatamos, também, o encorajamento da predição e da identificação das rimas, além de mais atenção à consciência fonológica. Percebemos que os alunos mais tímidos desenvolveram melhores habilidades de comunicação, tornando-se mais confiantes e seguros, ao lerem o poema ao final dos trabalhos.

\section{Considerações finais}

Muitos alunos que estão tendo dificuldade no letramento precisam entender que as palavras faladas e as sílabas consistem de sequências de sons da fala (fonemas). Esse entendimento, essencial para aprender a ler uma língua alfabética, porque as letras do alfabeto e as combinações de letras representam os sons básicos da fala, foi percebido com estas atividades. As crianças e a professora gostaram de brincar com as palavras. Para ela, um grande desafio, na empreitada de letrar, é ensinar habilidades básicas e fornecer ambientes de aprendizagem ricos, significativos e envolventes, suportados por práticas de ensino apropriadas, já que cada criança chega à sala de aula com diferentes experiências de alfabetização e habilidades distintas.

Então, é necessário considerar as necessidades de cada criança para fornecer programas equilibrados, com instruções explícitas, que contenham exercícios significativos de leitura e de escrita. Nesse sentido, há motivos para advogar em favor do uso de atividades com rimas que, nesta experiência, mostrou ser um excelente recurso pedagógico.

\section{Referências}

DEWHURST, Stephen; ROBINSON, Claire. False Memories in Children Evidence for a Shift from Phonological to Semantic Associations. Psychological Science, v. 11, n. 15, p. 782-786, nov. 2004.

GABLE, Sara. Promoting Young Children's Early Literacy. MissouriFamilies.org, 2010. Disponível em: $<$ http://missourifamilies.org/features/childcarearticles/childcare3.htm.>. Acesso em: 22 dez. 2013.

GOSWAMI, Usha. A special link between rhyming skill and the use of orthographic analogies by beginning readers. J Child psycho Psychiatry, n. 3, p. 301-11, jan. 1990.

JOHNSON, Janelle; HAYES, Donald. Preschool children's retention of rhyming and nonrhyming text: Paraphrase and rote recitation measures. Journal of Applied Developmental Psychology, n. 8, p. 317-327, jul./set. 1987.

QING-FENG, Li. Developing language skills through nursery rhymes. US-China Foreign Language, n. 5, p. 30-33, ago./out. 2007.

SHEINGOLD, Karen; FOUNDAS, Anne. Rhymes for some reasons: effect of rhyme on children's memory for detail and sequence in simple narratives. Psychological Reports, n. 43, p. 1231-1234, dez. 1978

VLOEDGRAVEN, Judith; VERHOEVEN, Ludo. Screening of phonological awareness in the early elementary grades: An IRT approach. Annals of Dyslexia, v. 57, p. 33-50, jan./mar. 2007. 
